\title{
The Effect of Stevia rebaudiana on the Growth and Survival of Lactobacillus rhamnosus GR-1 and Sensory Properties of Probiotic Yogurt
}

\author{
Alison Weber ${ }^{1} \&$ Sharareh Hekmat ${ }^{1}$ \\ ${ }^{1}$ Division of Food and Nutritional Sciences, Brescia University College, Western University, London, Ontario, \\ Canada \\ Correspondence: Sharareh Hekmat, Division of Food and Nutritional Sciences, Brescia University College, \\ Western University, London, Ontario, Canada, 1285 Western Road, London, Ontario, N6G 1H2, Canada. Tel: \\ 1-519-432-8353, ext. 28227. E-mail: hekmat@uwo.ca
}

\author{
Received: February 16, 2013 Accepted: March 15, 2013 Online Published: March 28, 2013 \\ doi:10.5539/jfr.v2n2p136 \\ URL: http://dx.doi.org/10.5539/jfr.v2n2p136
}

\begin{abstract}
This study evaluated the effect of various sweetening agents on sensory properties of probiotic yogurt. The growth and survival of Lactobacillus rhamnosus GR-1 in yogurt was measured at 1, 14 and 28 days of storage. Bacterial growth reached a range of $10^{8}-10^{9}$ Colony Forming Units (CFU) $\mathrm{ml}^{-1}$ over the storage period for six probiotic yogurt samples $(0.12 \%$ stevia, $0.12 \%$ stevia-inulin-chromium (SIC), $1.0 \%$ sucralose, $5.0 \%$ sucrose, $6.0 \%$ xylitol and a control). Sensory panelists $(\mathrm{n}=109)$ used a 9-point hedonic scale and evaluated five sensory characteristics (flavour, appearance, sweetness, texture, and overall quality) of the four sweetened probiotic yogurts $(0.12 \%$ stevia, $0.12 \%$ SIC, $1.0 \%$ sucralose and $5.0 \%$ sucrose $)$. The sucralose sample was significantly preferred for all five characteristics $(\mathrm{P}<0.001)$ and the sucrose sample was significantly liked more than both the stevia and SIC samples for all characteristics except flavour $(\mathrm{P}<0.001)$. Overall, the stevia sample received higher mean scores than the SIC sample.
\end{abstract}

Keywords: probiotic, yogurt, stevia, sensory evaluation, Lactobacillus rhamnosus GR-1

\section{Introduction}

There has been an increased consumer demand for low calorie functional foods for weight management and diabetes prevention and control. With increased consumer interest in reducing sugar intake, the use of artificial sweeteners during the last decade has triggered the development of new sugar free products (Pinheiro, Oliveira, Penna, \& Tamime, 2005). Probiotic yogurts are among functional dairy products that have contributed to the increasing growth in sales of functional foods (Agri-Food Canada, 2010). Currently, low calorie yogurts in the Canadian market are mostly artificially sweetened with sucralose, aspartame and acesulfame-k (Agri-Food Canada, 2011). Natural and low caloricsweeteners are warranted as consumers concern with these artificial sweeteners are evident (Agri-Food Canada, 2011). A low calorie, stevia sweetened yogurt may be an acceptable product on the market for diabetic diets or to aid in blood glucose control and weight management.

Stevia is a naturally occurring compound derived from the Stevia rebaudiana Bertoni shrub of the Asteracae family (Tavarini, Ribuoli, Bimbatti, \& Angelini, 2010). The stevia leaves contain the steviol glycoside extracts; stevioside and rebaudioside (Jeppesen et al., 2006; Tavarini et al., 2010). Stevia was historically used in Paraguay as a sweetener for medicinal drinks and tea (Goyal, Samsher \& Goyal, 2010). Stevia is also used in Brazil and Paraguay for natural control of diabetes (Jeppesen, 2006). Over 40 years ago, stevia was the sole sweetener in Japan (Goyal, Samsher, \& Goyal, 2010) and today it currently comprises $40 \%$ of the Japanese sweetener market (Jones, 2006). Stevia is also used as a food additive globally including many countries in South America and Asia (Jones, 2006). There has been resistance to the regulation of stevia; however, it has more recently been gaining approval as a sweetener or additive in Europe, the United States, Australia and New Zealand (Stevia Global Institute, 2013). In Canada, stevia is currently approved for its use in natural health products (NHPs) or as a sweetener; however, despite centuries of international use, it is currently not approved as an additive in commercial foods (Benford, Hill, Schlatter, \& DiNovi, 2008). The Joint Food and Drug Administration/World Health Organization's Expert Committee on Food Additives recommends the maximum limit for steviol glycosides in NHPs is of $4 \mathrm{mg}$ steviol $/ \mathrm{kg}$ body weight (Benford et al., 2008). The reported 
benefits of steviol glycosides include anti-hyperglycemic effects (Chan et al., 2000; Jeppesen, Gregersen, Alstrup, \& Hermansen, 2002), anti-hypertensive effects (Maki et al., 2008; Xi, Yamaguchi, Sato, \& Takeuchi, 1998), and antioxidant activity (Tavarini et al., 2010). As stevia does not have an effect on blood glucose or blood pressure, it is suited for diabetics and those intending to avoid sugar in their diets (Jeppesen et al., 2006).

To our knowledge, there are no studies reporting the acceptance of stevia as the only sweetener in probiotic yogurt by a large sample of Canadian consumers. Stevia and sucrose in strawberry flavoured yogurt has been evaluated for preference by Lisak, Jelicic, Tratnik and Bozanic (2011) through sensory evaluation. Sucrose, stevia and a combination of both sweeteners were each evaluated in yogurt by trained judges where the stevia samples were at concentrations of $0.03 \%, 0.045 \%$, and $0.06 \%$ (Lisak et al., 2011). This study concluded that the concentration of $4.5 \%$ of all sweeteners $(0.045 \%$ stevia $)$ was preferred in the following order: sucrose and stevia, sucrose, stevia (Lisak et al., 2011). Another sensory evaluation study examined the sweetness equivalence of various combinations of sweeteners in strawberry flavoured yogurt including stevia, aspartame, acesulfame-k, cyclamate, saccharin, sucralose and sucrose (Reis et al., 2011). Using the magnitude estimation method, sucralose was found to be the sweetest while the cyclamate/saccharin/stevia mixture scored low (Reis et al., 2011). Furthermore, sensory evaluation of powdered stevia in other dairy products (custard, kulfi and sandesh) found that a concentration of $0.25 \%$ stevia was acceptable within these products (Agarwal, Kochhar, \& Sachdeva, 2010). However, another study found that the sensory characteristics of yogurt sweetened with $0.04 \%$ of steviol glycosides included negative off flavour in comparison with the standard sucrose sweetened yogurt (Guggisberg, Piccinali, \& Schreier, 2011). Overall, the research suggests that stevia concentrations of $0.045 \%$ and $0.25 \%$ are adequate to impart sweetness or acceptability; however combinations of sweeteners may be more acceptable. The consumer acceptability of a probiotic yogurt sweetened with stevia is yet to be evaluated.

Probiotics, by definition are "live microorganisms which when administered in adequate amounts confer a health benefit on the host" (Food and Agricultural Organization, 2001). Lactobacillus rhamnosus GR-1 has demonstrated to be safe and bile tolerant such that it survives the passage through the intestine and is suitable for oral use (Gardiner et al., 2002). L. rhamnosus GR-1 has shown positive health related outcomes with its consumption. Randomized controlled and clinical trials of L. rhamnosus GR-1 have found immunity improvements (Anukam, Osazuwa, Osadolor, Bruce, \& Reid, 2008; Irvine et al., 2010), diarrhea relief (Anukam et al., 2008) and prevention of bacterial vaginosis and urogenital infections (Hummelen et al., 2010; Reid et al., 2001).

Acceptable levels of probiotic bacteria for therapeutic effects are to be greater than $1 \times 10^{7}$ Colony Forming Units (CFU) $\mathrm{ml}^{-1}$ at consumption (Ishibasi \& Shimamura, 1993) and may be even higher when accounting for losses through digestion and various bacterial strains as recommendations vary from $1 \times 10^{6}$ to $1 \times 10^{9} \mathrm{CFU} \mathrm{ml}^{-1}$ (Karimi, Mortazavian, \& Da Cruz, 2011). Evaluation of the growth and survival of L. rhamnosus GR-1 in milk observed microbial counts of $1 \times 10^{9} \mathrm{CFU} \mathrm{m}{ }^{-1}$ that decreased to $9 \times 10^{8} \mathrm{CFU} \mathrm{ml}^{-1}$ in 28 days (Hekmat \& Reid, 2007). Moreover, L. rhamnosus GR-1 survived significantly better than L. reuteri RC-14 specifically in yogurt with yeast extract additives for the 28 day storage period (Hekmat, Soltani, \& Reid, 2009). This indicates that the incorporation of L. rhamnosus GR-1 in yogurt for 28 days is feasible as it remains at levels required for therapeutic effects compared to another bacterial strain.

Preliminary research has found that individual samples of $0.04 \%$ stevia and $0.04 \%$ stevia-inulin-chromium (SIC) significantly increases the growth and survival of L. rhamnosus GR-1 in milk compared to $7 \%$ xylitol, $5 \%$ sucrose, and 1.25\% sucralose sweetened samples (Hekmat, 2011). Furthermore, it is also found that steviosides have antimicrobial effects, thusit my increase the shelf life of products (Puri \& Sharma, 2011). To our knowledge, no previous research has evaluated the effect of stevia or other sweetener agents on the growth of $L$. rhamnosus GR-1 in yogurt. The addition of stevia in probiotic yogurt may increase the functionality of probiotic yogurt by supporting the growth and survival of L. rhamnosus GR-1.

Theobjective of this study was to evaluate the use of various sweeteners, including stevia, and the effects on the growth and survival of the probiotic bacteria over the storage period as well as their effect on the sensory properties of probiotic yogurt.

\section{Materials and Methods}

\subsection{Probiotic Mother Culture Preparations}

Ten percent inoculums of L.rhamnosus GR-1 bacteria was added to sterilized Man, Ragosa and Sharp (MRS) broth (EM Science, Gibbstown, NJ) and incubated with a gas pack to achieve anaerobic conditions (BBL Gas $\mathrm{Pak}^{\mathrm{TM}}$ EZ, Becton Dickinson \& Co., Sparks, BD) at $37^{\circ} \mathrm{C}$ overnight (17-18 hours). This was used as the $L$. rhamnosus GR-1 stock solution. The probiotic mother culture was prepared by autoclaving $200 \mathrm{ml}$ of milk (1\% 
fat) at $15 \mathrm{psi}$ for $15 \mathrm{~min}$ and then it was cooled to $4^{\circ} \mathrm{C}$. The milk was then inoculated with $1 \%(\mathrm{wt} / \mathrm{vol})$ of $L$. rhamnosus GR-1 broth and incubated anaerobically (BBL Gas Pak, Becton Dickinson, \& Co., Sparks, MD) at $37^{\circ} \mathrm{C}$ overnight $(17-18 \mathrm{~h})$.

\subsection{Sweetened Probiotic Yogurt Production}

Six individual $200 \mathrm{ml}$ milk (1\%) samples were produced containing; $0.12 \%(\mathrm{wt} / \mathrm{vol})$ stevia (NuNaturals, Inc), $0.12 \%(\mathrm{wt} / \mathrm{vol}) \mathrm{SIC}\left(\mathrm{NOW}{ }^{\circledR}\right), 0.1 \%(\mathrm{wt} / \mathrm{vol})$ sucralose $\left(\mathrm{SPLENDA}^{\circledR}\right), 0.7 \%(\mathrm{wt} / \mathrm{vol})$ xylitol $\left(\mathrm{NOW}{ }^{\circledR}\right), 5.0 \%$ (wt/vol) sucrose (Redpath Ltd.) and a control with no added sweetener. These sweetened milk samples were heat treated to $87^{\circ} \mathrm{C}$ for $30 \mathrm{~min}$ in a double boiler and cooled to $37^{\circ} \mathrm{C}$ then inoculated with $4 \%$ of the L. rhamnosus GR-1 mother culture and 2\% of standard yogurt microorganisms (Lactobacillus delbrueckii ssp. bulgaricus and Streptococcus thermophilus). The samples were then incubated to ferment for approximately $6 \mathrm{~h}$ at $37^{\circ} \mathrm{C}$, cooled at $4^{\circ} \mathrm{C}$ overnight and stored for 28 days.

\subsection{Microbial Analysis}

Enumeration of L. rhamnosus GR-1 for all samples was completed at 1,14 , and 28 days of storage at $4{ }^{\circ} \mathrm{C}$ using the dilution and drop method. All sixsamples were diluted in sterile saline $(0.85 \%)$ to $10^{-1}, 10^{-3}, 10^{-5}, 10^{-6}$, and $10^{-7}$ dilution factors. $0.1 \mathrm{ml}$ of each dilution was plated with a calibrated pipette, in duplicate, on selective MRS (EMD Laboratories) agar containing $0.015 \mathrm{~g} \mathrm{~L}^{-1}$ of fusidic acid (Sigma Laboratories). Fusidic acid is added to the agar medium to increase selectivity of L. rhamnosus GR-1 (Gardiner et al., 2002). The plates were then inverted and incubated an aerobically at $37^{\circ} \mathrm{C}$ for $48 \mathrm{~h}$. Viable numbers were determined and recorded as CFU $\mathrm{ml}^{-1}$ based on colony counts. Duplicates of each plate were produced and an average count was determined for analysis. A second replication of this study was also performed with six new probiotic yogurt samples.

\subsection{Sensory Evaluation}

\subsubsection{Sensory Panelists}

The sensory testing phase was approved by the Western University Research Ethics Board and the Brescia University College Research Ethics Board and received a letter of no objection from Health Canada. All sensory testing was completed at the Brescia University College Sensory Testing Centre. The inclusion criteria required that panelists must be consumers of probiotic yogurt as evidenced by consumption of similar products within the past month and screened to be between the ages of 18 and 55 years old. Exclusion criteria for this study included those having lactose intolerance, dairy allergies, diabetes, high or low blood pressure, a plant allergy, or those who are pregnant or breast feeding. Panelists were recruited from both the Western University and Brescia University College. Participation of 80-100 panelists is recommended for hedonic acceptability tests (European Sensory Network, 2011). Panelists were recruited via posters, email and word of mouth. Eligible panelists received an information form, and signed an informed consent form prior to participating. The product usage questionnaire was used for screening purposesto generalize the data to yogurt consumers. An honorarium gift certificate was provided to all panelists.

\subsubsection{Sample Preparation}

A maximum of four samples were selected for the sensory evaluation. The selected yogurt samples for sensory evaluation included $0.12 \%(\mathrm{wt} / \mathrm{vol})$ stevia, $0.12 \%(\mathrm{wt} / \mathrm{vol}) \mathrm{SIC}, 1 \%(\mathrm{wt} / \mathrm{vol})$ sucralose and $5 \%(\mathrm{wt} / \mathrm{vol})$ sucrose. Probiotic yogurt was manufactured as was previously described. Sensory evaluation was performed one day post yogurt manufacture. Samples were presented in $30 \mathrm{~g}$ portions in transparent plastic cups, in a balanced random order, and labeled with random three digit codes to mask the identity.

\subsubsection{Sensory Evaluation}

Panelists were seated in individual booths within the sensory testing room, separate from the preparation area and instructed to remain silent throughout the evaluation in order to ensure accurate data collection. After providing informed consent, the panelists received a tray of the four coded yogurt samples $\left(4^{\circ} \mathrm{C}\right)$ in a balanced random order with a spoon, napkin, and a glass of water to cleanse the palate between evaluations.

Panelists were instructed to evaluate the samples from left to right and have some water between each yogurt sample. Panelists were asked to rate the yogurts on the characteristics of appearance, flavour, texture, sweetness, and overall acceptability for each yogurt using a nine point hedonic scale. The hedonic degree of liking scale ranges from one to nine where one corresponds with "dislike extremely" and nine corresponds with "like extremely". 


\subsection{Statistical Analysis}

Statistical analysis was conducted using SAS Ver 9.3 (SAS Institute Inc, Cary, NC). A one way repeated measure analysis of variance (ANOVA) based on Log transformed counts analyzed the treatment and shelf life effect on the viable microorganisms over time. For the sensory evaluation component of this study, a repeated measure ANOVA and Tukey's test $(\mathrm{P}<0.05)$ was used to test for significant differences between means.

\section{Results}

\subsection{Bacterial Enumeration}

Table 1 shows the descriptive statistics for the enumeration of $L$. rhamnosus GR-1 in sweetened yogurt over the 28 day storage period. All six samples had L. rhamnosus GR-1 growth beyond a mean of $1 \times 10^{8} \mathrm{CFU} \mathrm{ml}^{-1}(\mathrm{P}>$ 0.05 ) throughout the storage period of 28 days. The stevia and xylitol samples both grew beyond a mean of $1 \times 10^{9} \mathrm{CFU} \mathrm{ml}{ }^{-1}(\mathrm{P}>0.05)$ at day 28 . At 28 days, all samples had a higher mean value compared to day 1 with the exception of the SIC sample. There were no significant differences between treatments $(\mathrm{P}=0.504)$ or time $(\mathrm{P}=$ 0.340). There was no evidence of an interaction $(\mathrm{P}=0.992)$ or any differences within treatments $(\mathrm{P}=0.504)$ or time $(\mathrm{P}=0.340)$.

Table 1. The bacteria count $\left(\mathrm{CFU} \mathrm{ml^{-1 }}\right)$ of each sample over time (days)

\begin{tabular}{lccc}
\hline & 1 & 14 & 28 \\
\hline Control & $7.3 \mathrm{E}+08 \pm 3.2 \mathrm{E}+08$ & $1.3 \mathrm{E}+09 \pm 1.3 \mathrm{E}+09$ & $8.3 \mathrm{E}+08 \pm 4.6 \mathrm{E}+08$ \\
Stevia & $9.5 \mathrm{E}+08 \pm 2.8 \mathrm{E}+08$ & $8.8 \mathrm{E}+08 \pm 1.1 \mathrm{E}+08$ & $1.3 \mathrm{E}+09 \pm 9.2 \mathrm{E}+08$ \\
Sucrose & $5.4 \mathrm{E}+08 \pm 2.6 \mathrm{E}+08$ & $7.8 \mathrm{E}+08 \pm 4.6 \mathrm{E}+08$ & $9.2 \mathrm{E}+08 \pm 4.0 \mathrm{E}+08$ \\
SIC & $8.8 \mathrm{E}+08 \pm 5.3 \mathrm{E}+08$ & $8.5 \mathrm{E}+08 \pm 2.1 \mathrm{E}+08$ & $8.0 \mathrm{E}+08 \pm 4.9 \mathrm{E}+08$ \\
Sucralose & $6.3 \mathrm{E}+08 \pm 1.8 \mathrm{E}+08$ & $6.0 \mathrm{E}+08 \pm 0.0 \mathrm{E}+08$ & $9.5 \mathrm{E}+08 \pm 0.7 \mathrm{E}+08$ \\
Xylitol & $8.3 \mathrm{E}+08 \pm 4.6 \mathrm{E}+08$ & $1.4 \mathrm{E}+09 \pm 7.4 \mathrm{E}+08$ & $1.3 \mathrm{E}+09 \pm 2.5 \mathrm{E}+08$
\end{tabular}

As shown in Table 1, the descriptive statistics of ANOVA based on $\log$ transformed counts for viability of $L$.

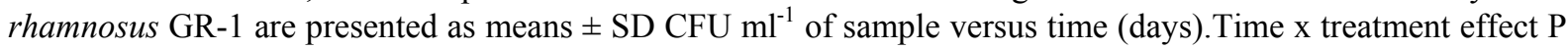
$=.992$, treatment effect $\mathrm{P}=.504$ and time effect $\mathrm{P}=.340$.

\subsection{Sensory Evaluation}

\subsubsection{Demographics and Product Usage Questionnaire}

One hundred ten panelists participated in this study; however, one participant was removed from the study because the inclusion criteria were not met for age. Majority of the participants were female (88\%) and the mean age of participants was 24 years old.

From the product usage questionnaire, the majority of panelists indicated that they usually prefer a flavoured, fruit bottom or fruit mixed yogurt. Based on the 9-point hedonic scale, the results for the mean ratings of appearance, flavour, sweetness, texture and overall quality scores are in table 1. Overall, the sucralose sample was significantly more liked $(\mathrm{P}<0.001)$ for all measured characteristics andstevia received higher $(\mathrm{P}<0.001)$ mean scores than the SIC sample.

\subsubsection{Appearance}

The yogurt was white in colour and had a thick and smooth consistency. The mean scores for the appearance of all samples was between liked slightly and liked moderately on the 9-point hedonic rating scale. There were significant differences between samples for mean appearance scores $(\mathrm{P}<0.001)$. The mean appearance scorefor the sucralose, sucrose, stevia, and SIC samples were $6.7 \pm 1.4,6.4 \pm 1.6,6.2 \pm 1.7$, and $6.2 \pm 1.6$ respectively. The sucralose sample was significantly more liked $(\mathrm{P}<0.001)$ than all other samples for appearance.

\subsubsection{Flavour}

The mean scoresfor flavour were significantly different between samples $(P<0.001)$. The flavour of the sucralose sample was significantly $(\mathrm{P}<0.001)$ more liked than all other samples. A mean score of $6.9 \pm 1.4$ for the sucralose sample indicated that it was moderately liked. The flavourof the sucrose sample was significantly more liked than both the stevia and SIC sample. The mean flavour scores of the stevia sweetened yogurt and the 
SIC sweetened yogurt were not significantly $(\mathrm{P}>0.05)$ different, however the stevia received a higher mean score of $4.7 \pm 4.5$ indicating it was neither liked nor disliked.

\subsubsection{Sweetness}

There were significant differences between samples for mean scores for sweetness $(\mathrm{P}<0.001)$. The mean score for sweetness for the sucralose sample was $6.8 \pm 1.8$ which was significantly $(\mathrm{P}<0.001)$ higher than the scores for stevia $(3.6 \pm 1.9)$, sucrose $(5.5 \pm 2.1)$, and SIC $(3.5 \pm 2.0)$. The sucrose sample was also significantly $(\mathrm{P}<$ 0.001 ) more liked for sweetness than stevia and SIC.

\subsubsection{Texture}

There were significant differences between mean scores for texture $(\mathrm{P}<0.001)$. The sucralose sample had a mean score of $6.8 \pm 1.8$ which was significantly $(\mathrm{P}<0.001)$ higher than the scores for all other samples. The sucrose mean score of $6.3 \pm 1.8$ was significantly higher $(\mathrm{P}<0.001)$ than stevia $(5.5 \pm 2.0)$ and SIC $(5.5 \pm 2.0)$, but not sucralose.

\subsubsection{Overall Quality: Like/Dislike}

There were significant differences between samples for mean scoresof overall like and dislike $(\mathrm{P}<0.001)$. The sucralose sample was significantly $(\mathrm{P}<0.001)$ more liked than all other samples and the sucrose sample was significantly $(\mathrm{P}<0.001)$ more liked than stevia and SIC. The mean scoresfor the stevia $(4.3 \pm 1.8)$ and SIC (3.9 $\pm 1.9)$ samples indicated that they were slightly disliked, whereas the sucralose sample $(6.8 \pm 1.5)$ was moderately liked and the sucrose sample $(5.8 \pm 1.9)$ was slightly liked.

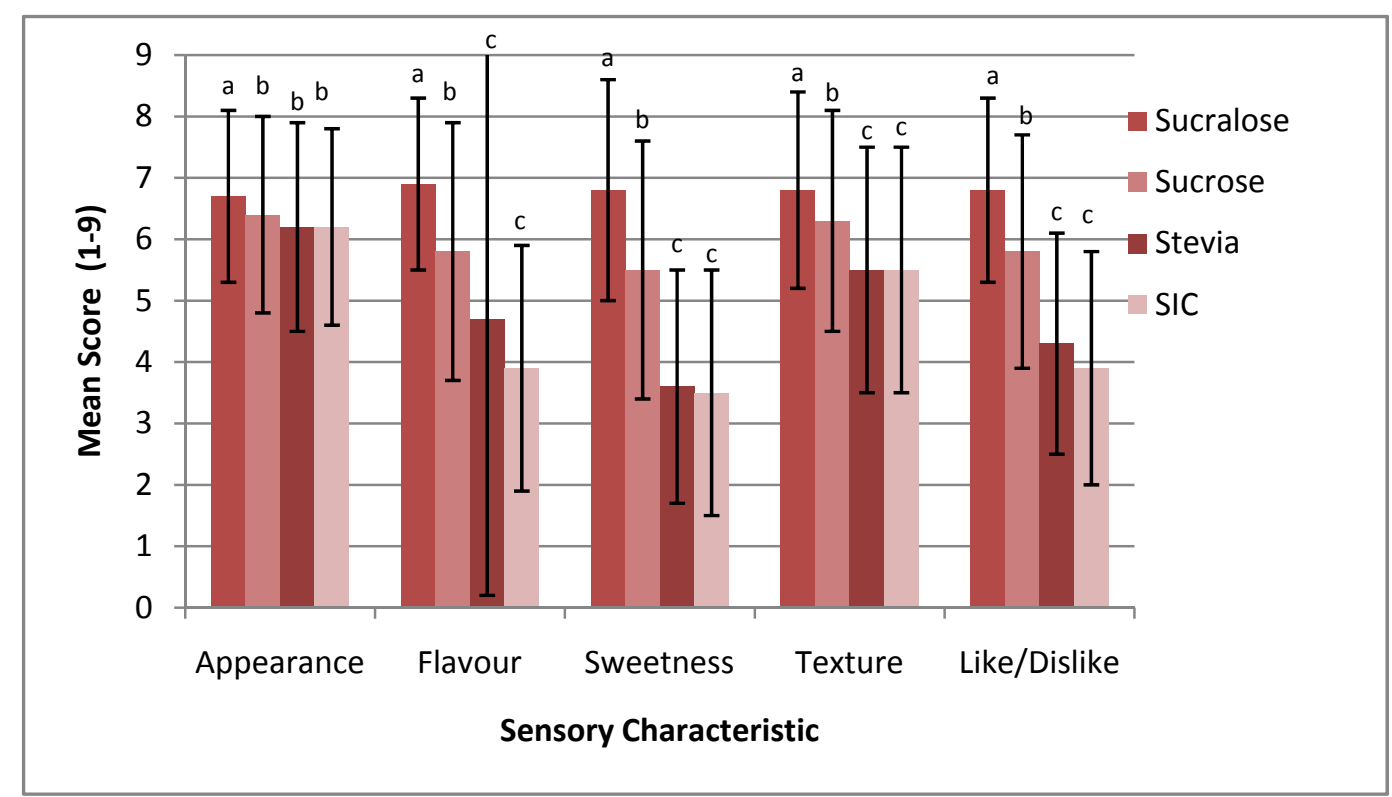

Figure 1. Panelists $(\mathrm{n}=109)$ mean sensory score and standard deviations for appearance, flavour, sweetness, texture and overall like/dislike on a 9 point hedonic scale for each sweetened sample

where $1=$ dislike extremely, $2=$ dislike very much, $3=$ dislike moderately, $4=$ dislike slightly, $5=$ neither like or dislike, $6=$ like slightly, $7=$ like moderately, $8=$ like very much, and $9=$ like extremely; $\mathrm{P}<0.001$ for all characteristics. For each characteristic, treatments with the same letter are not statistically different by a Tukey's Test at the significance level of $\mathrm{P}<0.05$.

\section{Discussion}

The primary outcome of this study was to observe the effect of various sweeteners on the growth and survival of L. rhamnosus GR-1. This study showed that the addition of various sweeteners to probiotic yogurt resulted in viable counts of the probiotic of interest, $L$. rhamnosus GR-1, to levels greater than the therapeutic level of $1 \times 10^{7}$ $\mathrm{CFU} \mathrm{m}{ }^{-1}$ of yogurt during a storage period of 28 days. This suggests that steviol glycosides are suitable to incorporate into a probiotic yogurt as they do not impair the growth of L. rhamnosus GR-1 and furthermore, it remains at a functional level at 28 days of storage. Our findings show that from day 1 to 28, L. rhamnosus GR-1 
grew from $9.5 \times 10^{8}$ to $1.3 \times 10^{9}$ and from $8.8 \times 10^{8}$ to $8.0 \times 10^{8} \mathrm{CFU} \mathrm{ml}^{-1}$ for stevia $(0.12 \%)$ and SIC $(0.12 \%)$ sweetened yogurt, respectively. This may indicate that stevia had a greater effect on the viability of $L$. rhamnosus GR-1 compared to SIC at 28 days.

The secondary outcome of this study was the effect of stevia, SIC, sucrose, and sucralose on sensory properties of probiotic yogurt. The sample sweetened with $5 \%$ sucralose was significantly $(\mathrm{P}<0.001)$ more liked than all other yogurt samples on all characteristics and $1 \%$ sucrose was significantly $(\mathrm{P}<0.001)$ more liked for appearance, sweetness, texture and overall quality than stevia and SIC. The sucrose samples were more preferred than stevia sweetened samples similar to the findings of Lisak et al. (2011). The lower score for stevia samplescould be due to lower concentration $(0.12 \%)$ which might be too low to impart comparable sweetness to the sucralose and sucrose samples. Agarwall et al. (2010) had determined that a concentration of $0.25 \%$ stevia in fermented dairy products was the most acceptable level, however Lisak et al. (2011) suggested a combination of sucrose and stevia at a $4.5 \%$ concentration was most preferred.

The use of artificial flavouring may have also increased the sensory properties of the stevia sweetened samples. As indicated by the usage questionnaire, most participants prefer flavoured, fruit bottom, or stirred yogurt over plain yogurt. The sweetened yogurt in this study was unflavored and did not contain any fruit. Interestingly, the standard deviation for the mean flavour rating for stevia was 4.5 indicating that there is a large range of scores for this sample. This may indicate that there is a potential market for stevia sweetened yogurt for certain individuals.

\section{Conclusion}

Viable counts of L. rhamnosus GR-1 were higher than the reported therapeutic value of $10^{7} \mathrm{CFU} \mathrm{ml}{ }^{-1}$ for all samples, indicating that stevia, stevia-inulin chromium, sucralose and sucrosecould successfully be incorporated in probiotic yogurt. Our sensory evaluation showed that yogurt sweetened with sucralose $(5 \%)$ was most preferred and a formulation containing stevia may require a higher concentration and further investigation. To add to these findings, future research on the growth of L. rhamnosus GR-1 in yogurt should include various prebiotics such as inulin and fructooligosaccharidesin combination with stevia. Further research on the sensory profile of stevia sweetened dairy products should evaluate various concentrations of stevia and in combination with flavoured yogurts.

\section{Acknowledgments}

The authors are thankful of Adriana Cimo and Mohammad Soltani or their roles in laboratory preparation, recruiting participants and sensory evaluation. We also acknowledge the Division of Food and Nutritional Sciences at Brescia University College for providing funding and the laboratory facilities to which this study was performed.

\section{References}

Agarwal, V., Kochhar, A., \& Sachdeva, R. (2010). Sensory and nutritional evaluation of sweet milk products prepared using stevia powder for diabetics. Studies on Ethno-Medicine, 4(1), 9-13.

Agri-FoodCanada. (2010). Health and Wellness Trends. U.S. Market. Retrieved December 21, 2012, from http://www.ats-sea.agr.gc.ca/amr/5526-eng.htm\#b

Agri-FoodCanada. (2011). Consumer Trends. Food for Individuals with Diabetes in the United States. Retrieved December 21, 2012, from http://www.ats-sea.agr.gc.ca/amr/5726-eng.htm\#f

Anukam, K. C., Osazuwa, E. O., Osadolor, H. B., Bruce, A. W., \& Reid, G. (2008). Yogurt containing probiotic lactobacillus rhomnosus GR-1 and L-reuteri RC-14 helps resolve moderate diarrhea and increases CD4 count in HIV/AIDS patients. Journal of Clinical Gastroenterology, 42(3), 239-243. http://dx.doi.org/10.1097\%2FMCG.0b013e31802c7465

Benford, D. J., Hill, F., Schlatter, J., \& DiNovi, M. (2009). Steviol Glycosides (addendum). In Joint FAO/WHO Expert Committee on Food Additives (JECFA), Safety evaluation of certain food additives. Sixty-ninth meeting: $\quad$ Food additives (pp. 183-219). $\quad$ Retrieved from http://www.inchem.org/documents/jecfa/jecmono/v60je01.pdf

Chan, P., Tomlinson, B., Chen, Y. J., Liu, J. C., Hsieh, M. H., \& Cheng, J. T. (2000). A double-blind placebo-controlled study of the effectiveness and tolerability of oral stevioside in human hypertension. $\begin{array}{lllll}\text { British Journal of } & \text { Clinical } & \text { Pharmacology, } & \text { 50(3), }\end{array}$ http://dx.doi.org/10.1046/j.1365-2125.2000.00260.x 
European Sensory Network. (2011). Guidelines for consumer testing - guidance from ESN members. Retrieved from http://www.esn-network.com/990.html

Food and Agricultural Organization/World Health Organization (FAO/WHO). (2001). Health and nutritional properties of probiotics in food including powder milk with live lactic acid bacteria. Retrieved from http://www.who.int/foodsafety/publications/fs_management/en/probiotics.pdf

Gardiner, G. E., Heinemann, C., Baroja, M. L., Bruce, A. W., Beuerman, D., Madrenas, J., \& Reid, G. (2002). Oral administration of the probiotic combination lactobacillus rhamnosus GR-1 and L-fermentum RC-14 for human intestinal applications. International Dairy Journal, 12(2-3), 191-196. http://dx.doi.org/10.1016/S0958-6946(01)00138-8

Goyal, S. K., \& Samsher, G. R. K. (2010). Stevia (Stevia rebaudiana) a bio-sweetener: a review. International Journal of Food Science and Nutrition, 61(1), 1-10. http://dx.doi.org/10.3109/09637480903193049.

Guggisberg, D., Piccinali, P., \& Schreier, K. (2011). Effects of sugar substitution with stevia, actilight (TM) and stevia combinations or palatinose (TM) on rheological and sensory characteristics of low-fat and whole milk set yoghurt. International Dairy Journal, 21(9), 636-644. http://dx.doi.org/10.1016/j.idairyj.2011.03.010

Hekmat, S. (2011). The effect of different sweeteners on growth and survival ofLactobacillus rhamnosus GR-1 in milk [Abstract]. Journal of Dairy Science, 94, 291.

Hekmat, S., \& Reid, G. (2007). Survival of lactobacillus reuteri RC-14 and lactobacillus rhamnosus GR-1 in milk. International Journal of Food Science and Technology, 42(5), 615-619. http://dx.doi.org/10.1111/j.1365-2621.2006.01292.x

Hekmat, S., Soltani, H., \& Reid, G. (2009). Growth and survival of lactobacillus reuteri RC-14 and lactobacillus rhamnosus GR-1 in yogurt for use as a functional food. Innovative Food Science \& Emerging Technologies, 10(2), 293-296. http://dx.doi.org/10.1016/j.ifset.2008.10.007

Hummelen, R., Changalucha, J., Butamanya, N. L., Cook, A., Habbema, J. D. F., \& Reid, G. (2010). Lactobacillus rhamnosus GR-1 and L. reuteri RC-14 to prevent or cure bacterial vaginosis among women with HIV. International Journal of Gynecology \& Obstetrics, 111(3), 245-248. http://dx.doi.org/10.1016/j.ijgo.2010.07.008

Irvine, S. L., Hummelen, R., Hekmat, S., Looman, C. W. N., Habbema, J. D. F., \& Reid, G. (2010). Probiotic yogurt consumption is associated with an increase of CD4 count among people living with HIV/AIDS. $\begin{array}{llll}\text { Journal of Clinical Gastroenterology, } & \text { 44(9), }\end{array}$ http://dx.doi.org/10.1097/MCG.0b013e3181d8fba8

Ishibasi, N., \& Shimamura, S. (1993). Bifidobacteria - research and development in japan. Symp on Bifido-Bacteria-Old Concepts: New Food Products, at the 1992 Annual Meeting of the Inst of Food Technologists, 47(6), 126.

Jeppesen, P., Barriocanal, L., Meyer, M. T., Palacios, M., Canete, F., Benitez, S., ... Jimenez, J. T. (2006). Efficacy and tolerability of oral stevioside in patients with type 2 diabetes: A long-term, randomized, double-blinded, placebo-controlled study. Diabetologia, 49, 511-512.

Jeppesen, P., Gregersen, S., Alstrup, K., \& Hermansen, K. (2002). Stevioside induces antihyperglycaemic, insulinotropic and glucagonostatic effects in vivo: Studies in the diabetic goto-kakizaki (GK) rats. Phytomedicine, 9(1), 9-14. http://dx.doi.org/10.1078/0944-7113-00081

Jones, G. (2006). Stevia. NebGuide: University of Nebraska-Lincoln Institute of Agriculture and Natural Resources. Retrieved from http://www.ianrpubs.unl.edu/pages/publicationD.jsp?publicationId=609

Karimi, R., Mortazavian, A. M., \& Da Cruz, A. G. (2011). Viability of probiotic microorganisms in cheese during production and storage: A review. Dairy Science \& Technology, 91(3), 283-308. http://dx.doi.org/10.1007/s13594-011-0005-x

Lisak, K., Jelicic, I., Tratnik, L., \& Bozanic, R. (2011). Influence of sweetener stevia on the quality of strawberry flavoured fresh yoghurt. Mljekarstvo, 61(3), 220-225.

Maki, K. C., Curry, L. L., Carakostas, M. C., Tarka, S. M., Reeves, M. S., Farmer, M. V., ... Bisognano, J. D. (2008). The hemodynamic effects of rebaudioside A in healthy adults with normal and low-normal blood pressure. Food and Chemical Toxicology, 46(7), S40-S46. http://dx.doi.org/10.1016/j.fct.2008.04.040 
Pinheiro, M. V. S., Oliveira, M. N., Penna, A. L. B., \& Tamime, A. Y. (2005). The effect of different sweeteners in low-calorie yogurts - A review. International Journal of Dairy Technology, 58(4), 193-199.

Puri, M., \& Sharma, D. (2011). Antibacterial activity of stevioside towards food-borne pathogenic bacteria. Engineering in Life Sciences, 11(3), 326-329. http://dx.doi.org/10.1002/elsc.201000142

Reid, G., Bruce, A. W., Fraser, N., Heinemann, C., Owen, J., \& Henning, B. (2001). Oral probiotics can resolve urogenital infections. FEMS Immunol Med Microbiol., 30, 49-52. http://dx.doi.org/10.1016/S0928-8244(00)00233-9

Reis, R. C., Minim, V. P. R., Bolini, H. M. A., Dias, B. R. P., Minim, L. A., \& Ceresino, E. B. (2011). Sweetness equivalence of different sweeteners in strawberry-flavored yogurt. Journal of Food Quality, 34(3), 163-170. http://dx.doi.org/10.1111/j.1745-4557.2011.00378.x

Stevia Global Institute. (2013). Regulatory. Retrieved from http://www.globalsteviainstitute.com/en/Default/ResourceLibrary/Regulatory.aspx

Tavarini, S., Ribuoli, M., Bimbatti, M., \& Angelini, L. G. (2010). Functional components from stevia rebaudiana bert. leaves. Journal of Biotechnology, 150, S326-S326.

Xi, Y., Yamaguchi, T., Sato, M., \& Takeuchi, M. (1998). Antioxidant mechanism of stevia rebaudiana extract and antioxidant activity of inorganic salts. Journal of the Japanese Society for Food Science and Technology-Nippon Shokuhin Kagaku Kogaku Kaishi, 45(5), 317-322. 